\title{
The Facts about Truthmaking: An Argument for Truthmaker NeCESSITARIANISM
}

\author{
JAMIN ASAY \\ The University of Hong Kong
}

\begin{abstract}
Truthmaker necessitarianism is the view that an object is a truthmaker for a truthbearer only if it is impossible for the object to exist and the truth-bearer be false. While this thesis is widely regarded as truthmaking "orthodoxy", it is rarely explicitly defended. In this paper I offer an argument in favor of necessitarianism that raises the question of what the truthmakers are for the truths about truthmaking. The supposed advantages of non-necessitarianism dissolve once we take these truths into account.
\end{abstract}

$\mathrm{T}$ RUTHMAKER theory is notorious for relying on strong metaphysical principles for which it often doesn't have an argument. "I do not have any direct argument," David Armstrong says of the case for his central thesis that all truths have truthmakers (2004: 7; cf. Bigelow 1988: 123). Likewise, little argument is given for another key thesis about truthmaking: necessitarianism. Necessitarianism states that an object is a truthmaker for a claim only if it is metaphysically impossible for that object to exist, and yet the claim be false. Several writers have declared that necessitarianism is now "orthodoxy" in the truthmaking literature. ${ }^{1}$ There is, however, dissent to be found. ${ }^{2}$ My goal is to provide the orthodoxy with an actual argument.

Necessitarianism states a necessary condition on truthmaking, a condition which may or may not hold regardless of what else (if anything) one takes to be involved in truthmaking. Truthmaking, for example, may be a form of essential dependence (Lowe 2007), grounding (Schaffer 2010), or taken as primitive (Rodriguez-Pereyra 2005); for each view the question arises as to whether or not

1. E.g., Merricks (2007: 5), Cameron (2008: 107), Schaffer (2008: 10), and Goff (2010).

2. E.g., Parsons (1999), Heil (2000), Mellor (2003), Schaffer (2010), and Briggs (2012); Griffith (2015) rejects necessitarianism only for negative truths. 
truthmaking requires necessitating truthmakers. The appeal of necessitarianism is easy to appreciate. A truthmaker is supposed to account for, ground, or in some sense explain a truth-bearer's truth. Suppose some object $T$ is offered as a candidate truthmaker for some truth $\langle p\rangle$, but also that $T^{\prime}$ s existence is consistent with $\langle p>$ being false. That is to say, given T's existence, $\langle p\rangle$ may be true, or it may be false. In those cases where $\langle p\rangle$ is true, something else must be around to separate the situation from those where $\langle p\rangle$ is false. That something else, then, is highly relevant to the account of why $\langle p\rangle$ is true, and so deserves to figure into the truthmaker for $\langle p\rangle$. Armstrong offers a defense of necessitarianism along these lines (2004: 6-7; see also Bigelow 1988: 126), though it is not particularly compelling to his critics (e.g., Briggs 2012: 22). I happen to find his reasoning sound, but am interested in offering a new line of argument for his conclusion.

My argument revolves around the facts (i.e., true propositions) about truthmaking itself. Suppose $\mathrm{T}$ is a truthmaker for $\langle p\rangle$. If so, $\langle p\rangle$ is true, and so too is the truthmaking proposition $<\mathrm{T}$ makes true $\langle p\rangle>$. My focus is on the grounds for these facts about truthmaking. According to necessitarians (e.g., Armstrong 2004: 9), the members of the truthmaking relation suffice for making true the propositions about truthmaking. (This view, strictly speaking, isn't logically forced onto necessitarians; rather, it's a simple and straightforward view that is available to them.) In other words, if $\mathrm{T}$ makes true $\langle p\rangle$, then $\mathrm{T}$ and $\langle p\rangle$ together (or their mereological sum) make true $\langle$ T makes true $\langle p\rangle\rangle$. No additional ontological resources are needed to make true the truthmaking fact; that $\mathrm{T}^{\prime} \mathrm{s}$ existence guarantees the truth of $\langle p\rangle$ is necessary, and so necessitarians have a principled basis for concluding that $\mathrm{T}$ and $\langle p\rangle$ together are sufficient for grounding $<\mathrm{T}$ makes true $\langle p\rangle$. If something about the natures of $\mathrm{T}$ and $\langle p\rangle$ demonstrates that the former is a truthmaker for the latter, then these things are themselves appropriate grounds for the facts about what they make true. (In fact, if truth-bearers are necessary existents, then $\mathrm{T}$ itself might be thought sufficient to do the truthmaking for not only $\langle p\rangle$, but all the facts about what T makes true as well.) Hence, necessitarians have a straightforward and principled account of the truthmakers for the facts about truthmaking that introduces no further ontological requirements.

What can non-necessitarians say about truthmaking facts? Consider a case where $\mathrm{T}$ is a truthmaker for $\langle p\rangle$, but $\mathrm{T}$ does not necessitate $\langle p\rangle$. That means that it's possible for $\mathrm{T}$ to exist and $\langle p\rangle$ fail to be true. Hence the material conditional $<$ If T exists, then T makes true $\langle p\rangle>$ is only contingently true. This is the sense in which I shall loosely speak of the truthmaking fact $\langle$ T makes true $\langle p\rangle>$ being contingent. It's possible that $\mathrm{T}$ could have existed and yet not made $\langle p\rangle$ true. So at least some truthmaking facts for non-necessitarians are contingent-that is to say, they remain contingent even after T's existence is assumed. (Presumably some are necessary, even for non-necessitarians: $<$ Kripke makes true $<$ Kripke exists $>>$ is necessary in the sense that if Kripke exists, then he must make true 
$<$ Kripke exists>.) The question now arises for non-necessitarians as to what, if anything, makes contingent truthmaking facts true. I consider each available answer in turn. My conclusion is that non-necessitarians have no good option when it comes to the accounting of contingent truthmaking propositions. Necessitarians and their simple, straightforward account thus enjoy a significant theoretical advantage.

The first possibility is that nothing makes such facts true: they are truthmaker gaps. The tenability of this position depends on one's wider views about truthmaking. For maximalists, who believe that all truths have truthmakers, this view is a non-starter. For non-maximalists, truthmaker gaps still must be handled with care. One option is to treat such truths as being metaphysically brute: it's true that T makes true $\langle p\rangle$, but there is no further accounting to be had of such a truth. This response is rather extreme, and out of the basic spirit of truthmaker theory. The maneuver has precedents - see Sorenson (2001) on the truth-tellerbut it tends to be a view of last resort (and in Sorenson's case, a view only to be taken when we have no idea of the truth-value of the proposition in question and its negation). Truthmaker theory inherits its plausibility from the idea that truth is not a brute feature of the world: the alethic facts (i.e., the facts about the truthvalues of truth-bearers) are dependent upon non-alethic matters. That claims about truthmaking should fail to live up to the spirit of truthmaking would be an unfortunate and ironic consequence for non-necessitarians. At the very least, necessitarians enjoy a significant advantage over this 'brutalist' position by not requiring the infinitely many facts about truthmaking to be metaphysical bedrock.

There are gentler ways of handling truthmaker gaps. Rather than treating them as brute, one might argue that the nature of the truths in question reveals that they don't need a truthmaker. This perspective is taken by those who believe that negative existentials do not require truthmakers (e.g., Bigelow 1988). According to this outlook, for $<$ Leprechauns don't exist $>$ to be true, there doesn't need to be some other kind of thing in existence. The truth concerns what doesn't exist, not what does, and so requires no truthmaker to be true. This stance is controversial, but it's not some simple ad hoc rejection of maximalism. Furthermore, there is no slippery slope from some truths not needing truthmakers to all truths not needing truthmakers. It doesn't follow from $<$ Leprechauns don't exist $>$ needing no truthmaker that <The mascot of Notre Dame is the leprechaun> doesn't need one either. The relevant question for the non-necessitarian considering non-maximalism about truthmaking facts is whether they are relevantly analogous to facts about what doesn't exist. And it appears not. The claim that T makes true $\langle p\rangle$ is a positive claim about the 'alethic structure' of the world. It posits a contingently existing dependence between $\mathrm{T}$ and the truth of $\langle p\rangle$. As a result, I see no headway to be made on the view that contingent truthmaking facts are plausible truthmaker gaps. 
It seems, then, that non-necessitarians need to find truthmakers for the facts about truthmaking. Reserve ' $U$ ' for the name of the truthmaker for $<T$ makes true $\langle p\rangle>$, the proposition which I'll now call ' $\langle q\rangle$ '. So we have another truthmaking fact $\left({ }^{\prime}\langle r\rangle^{\prime}\right)$ on our hands: $\langle\mathrm{U}$ makes true $\langle q\rangle>$. (Its truthmaker will become relevant below.) $U$ either necessitates $\langle q\rangle$ or it doesn't. (Both options are available to non-necessitarians.) Suppose it does. In that case, U's existence guarantees that $\mathrm{T}$ makes true $\langle p\rangle$. Hence, $\mathrm{U}^{\prime}$ 's existence also guarantees T's existence, plus the truth of $\langle p\rangle$. Because $\mathrm{U}$ and $\mathrm{T}$ are not identical (if they were, $\mathrm{T}$ would necessitate $\langle p\rangle$ ), this view imposes the cost of forcing a necessary connection between distinct individuals: U can't exist unless T does as well. Furthermore, given that $U$ does guarantee the truth of $\langle p\rangle$ (and T doesn't), it's unclear why the non-necessitarian doesn't just cite $U$ in the first place as the truthmaker for $\langle p\rangle$, and thereby concede necessitarianism. (This point echoes Armstrong's argument above.) Presumably, the non-necessitarian sought the advantage of only needing $\mathrm{T}$ - and not $\mathrm{U}$, something over and above it - in order to account for $\langle p\rangle$. But on the current view of truthmaking facts, $U$ makes its appearance anyway to account for what makes it true that $\mathrm{T}$ makes true $\langle p\rangle$. The supposed gains in ontological economy that non-necessitarians can boast with respect to 'first-order' truths evaporate as soon as we seek out truthmakers for 'second-order' truths about what the truthmakers are for those first-order truths.

We come now to the view that contingent truthmaking facts do have truthmakers, but non-necessitating ones. On this view, $\langle\mathrm{U}$ makes true $\langle q\rangle>$ is contingent, just like $\langle q\rangle$ is. One question that immediately arises is what makes this third truth (a 'third-order' claim) true. The arguments above can be recycled again, and so the non-necessitarian will need to posit some non-necessitating truthmaker $\mathrm{V}$ for $\langle r\rangle$. We are well on the way to an infinite regress here of more and more contingent truthmakers for higher- and higher-order truthmaking claims. Once we open the door to non-necessitating truthmakers, we appear to need infinitely many of them.

Given that necessitarians need only the original truthmaker in question, this regress is a significant cost, to put it mildly, for their opponents. First, there is the straightforward ontological cost of accepting $\mathrm{U}, \mathrm{V}, \mathrm{W}$, and the rest. These ontological commitments are bypassed by the necessitarian, who thus earns a leaner ontology. Second, there is the fact that non-necessitarians end up committed to not just a larger ontology, but an infinitely large ontology, and simply in virtue of their view about the truthmaking relation. This is a startling metaphysical consequence, one which would need far greater theoretical support than what one could extract merely from thinking about the truthmaking relation. In developing their overall ontological view, truthmaker theorists seek to develop the most theoretically economical ontology that can be employed to ground all the truths. By putting one truthmaker (rather than infinitely many) to work as the grounds 
for infinitely many truths, necessitarians secure an important advantage over their opponents.

Here is another troubling consequence of the regress (this one courtesy of an anonymous referee). Higher-order truthmaking facts entail lower-order truthmaking facts. $<\mathrm{U}$ makes true $<\mathrm{T}$ makes true $\langle p\rangle>>$ entails $<\mathrm{T}$ makes true $\langle p\rangle$, which entails $\langle p\rangle$. Suppose an entailment principle is true, such that any truthmaker for a proposition is a truthmaker for any proposition entailed by the original proposition. In that case, all the infinitely many distinct truthmakers for the higher-order truthmaking facts are also truthmakers for the ground-level facts. Put succinctly: if $\langle p\rangle$ has $\mathrm{T}$ for a non-necessitating truthmaker, then it has infinitely many other distinct, non-necessitating truthmakers $(\mathrm{U}, \mathrm{V}, \mathrm{W}$, etc.). To have one truthmaker is to have infinitely many.

The basic regress argument, then, shows that non-necessitarians require an infinite ontology to ground all of the infinitely many truthmaking facts associated with every single ground-level fact. When the regress is paired with an entailment principle, we see that a single ground-level truth, all on its own, generates an infinitely large ontology of truthmakers. Of course, entailment principles are controversial, and not everyone accepts them (e.g., Rodriguez-Pereyra 2006). But it's worth noting that the major source of skepticism about them doesn't apply in this case. In cases of 'non-relevant' entailment, such as holds between $<$ Socrates exists $>$ and $\langle 7+5=12>$, one might argue that truthmaking doesn't travel with the entailment (see Armstrong 2004: 10-12). But the case of entailment between $<\mathrm{T}$ makes true $\langle p\rangle\rangle$ and $\langle p\rangle$ would seem to be secure under any model of relevancebased entailment. So any non-necessitarian who accepts even a weaker version of an entailment principle faces the problem.

There is one way for the non-necessitarian to stop the regress. Take $T, U, V$, and everything else up the chain to be one and the same. This view parallels the necessitarian's view. For necessitarians, if T makes true $\langle p\rangle$ as a matter of necessity, then it can also make true, as a matter of necessity, $\langle$ T makes true $\langle p\rangle>,<\mathrm{T}$ makes true $\langle$ T makes true $\langle p\rangle>>$, and all the others. (Recall again the caveat that perhaps the truth-bearers themselves will also figure into the higher-order truthmaking facts.) The non-necessitarian might claim similarly that because $T$ makes true $\langle p\rangle$, it also (perhaps in concert with $\langle p\rangle$ ) makes true $\langle$ T makes true $\langle p\rangle>$ and the others up the chain. T by itself doesn't guarantee the truth of $\langle q\rangle$ or $\langle r\rangle$ any more than it guarantees the truth of $\langle p\rangle$. But that of course is no objection to the non-necessitarian.

The problem here for the non-necessitarian is that this perspective doesn't make sense in the context of contingent truthmaking facts. It makes perfect sense for necessitarians. When $\mathrm{T}$ is a (necessitating) truthmaker for $\langle p\rangle$, it's presumably something about the nature or essence of $\mathrm{T}$ and $\langle p\rangle$ that ties them together. Nothing outside of the truthmaking relation is necessary to account for why the truth- 
making relation holds. All the higher-order facts about truthmaking concerning $\mathrm{T}$ and $\langle p\rangle$ immediately follow. But when it comes to the non-necessitarian's contingent truthmaking facts, this perspective is unavailable. According to the non-necessitarian, $\mathrm{T}$ does make true $\langle p\rangle$, but $\mathrm{T}$ itself is not responsible for this relationship; that's the basic premise of the non-necessitarian's view. Sometimes T makes true $\langle p\rangle$, sometimes it doesn't. It's nothing about $\mathrm{T}$ itself that makes the difference between the two cases - if the obtaining of the truthmaking in question were due solely to $\mathrm{T}$, then $\mathrm{T}$ would be a necessitating truthmaker. Hence, the basic commitment of the non-necessitarian is that something other than $\mathrm{T}$ is responsible for T's making true $\langle p\rangle$ : $\mathrm{U}, \mathrm{V}$, and the rest cannot be identical to $\mathrm{T}$. The non-necessitarian needs a distinct $U$ that accounts for why T makes true $\langle p\rangle$. And as before, if $U$ itself is a necessitator, then all along it was the truthmaker for $\langle p\rangle$, and if it's not, then we're back on the regress of infinitely many distinct individuals.

To solidify the argument, consider a particular example of the kind that tends to motivate the non-necessitarian view. Negative existentials and universal generalizations are the bugbears of necessitarian truthmaker theory. To find truthmakers for them, necessitarians are driven to suspiciously ad hoc ontological posits such as absences (Martin 1996) or totalities (Armstrong 2004). It's true, for instance, that all official copies of the international kilogram prototype are located in France. There are six such copies, and they all reside within the Pavillon de Breteuil in Sèvres, just outside Paris. Label them 'A' through ' $F$ '. Suppose we have a truthmaker for $<\mathrm{A}$ is an official copy of the international kilogram prototype and is located in France>; call it ' $T_{A}$ ', and suppose the same for the rest of the copies. $\mathrm{T}_{\mathrm{A}}$ through $\mathrm{T}_{\mathrm{F}}$ collectively (or their mereological sum) make it true that each of the six official copies are in France. They do not, however, necessitate the truth of $<$ All official copies of the international kilogram prototype are located in France $>$. The International Bureau of Weights and Measures could have decided to make a lucky seventh copy after finishing $\mathrm{A}$ through $\mathrm{F}$, and then shipped it off to Antarctica for safekeeping. In that case, the collection of $\mathrm{T}_{\mathrm{A}}$ through $\mathrm{T}_{\mathrm{F}}$ exists, though $<$ All official copies of the international kilogram prototype are located in France $>$ is false.

Necessitarians cannot cite $T_{A}$ through $T_{F}$ as the truthmaker for the generalization, because they don't guarantee that A through $\mathrm{F}$ are the only instances of the generalization. Hence, the necessitarian has a need for there to be, in addition to $\mathrm{T}_{\mathrm{A}}$ through $\mathrm{T}_{\mathrm{F}}$, an absence of other instances, or for A through $\mathrm{F}$ to figure into some totality of instances, or something similar. The non-necessitarian balks at this juncture, and claims that $\mathrm{T}_{\mathrm{A}}$ through $\mathrm{T}_{\mathrm{F}}$ are good enough to ground the truth of $<$ All official copies of the international kilogram prototype are located in France $>$. For the generalization to be true, all the instances need to be true. There are six instances, and $T_{A}$ through $T_{F}$ take care of establishing their truth. So $T_{A}$ 
through $\mathrm{T}_{\mathrm{F}}$ can serve as the truthmakers, albeit non-necessitating truthmakers, for the generalization. (See Mellor 2003: 214 for a defense of this line.)

Now consider how my argument plays out for the non-necessitarian. What is the truthmaker for $<\mathrm{T}_{\mathrm{A}}$ through $\mathrm{T}_{\mathrm{F}}$ make true $<$ All official copies of the international kilogram prototype are located in France $>$ ? It's against the spirit of truthmaker theory to take it as a brute truth, and it's not assimilable to the case of negative existentials. If the truthmaker turns out to be a necessitator such as an absence or totality (i.e., it's the absence of any further instances that makes $\mathrm{T}_{\mathrm{A}}$ through $\mathrm{T}_{\mathrm{F}}$ responsible in this case), then no advantage is gained over the necessitarian. If the truthmaker is some further entity distinct from $\mathrm{T}_{\mathrm{A}}$ through $\mathrm{T}_{\mathrm{F}}, \mathrm{a}$ regress is generated that requires infinitely more distinct objects to account for the relevant higher-order claims. And, finally, the collection of $T_{A}$ through $T_{F}$ is an inappropriate truthmaker for $<\mathrm{T}_{\mathrm{A}}$ through $\mathrm{T}_{\mathrm{F}}$ make true $<$ All official copies of the international kilogram prototype are located in France $>>$. It's nothing about $\mathrm{T}_{\mathrm{A}}$ through $\mathrm{T}_{\mathrm{F}}$ that accounts for why they are the truthmaker for the generalization. Those six objects are truthmakers in the actual world only because nothing besides $A$ through $F$ is an instance of the generalization. But $T_{A}$ through $T_{F}$ have no bearing on the issue of whether or not there are other instances of the universal; $\mathrm{T}_{\mathrm{A}}$ through $\mathrm{T}_{\mathrm{F}}$ ground no fact about how many total instances there are. The existence of $\mathrm{T}_{\mathrm{A}}$ through $\mathrm{T}_{\mathrm{F}}$, in other words, is completely independent of the existence of any other possible instances. Yet $\mathrm{T}_{\mathrm{A}}$ through $\mathrm{T}_{\mathrm{F}}$ 's being the truthmakers in the actual world crucially relies on there being no other instances. Since $T_{A}$ through $\mathrm{T}_{\mathrm{F}}$ have absolutely no 'say' regarding those other instances (in a necessitating way or not), they have absolutely no say in whether or not they make true the generalization.

I maintain, then, that necessitarians enjoy a very strong advantage over non-necessitarians. The supposed ontological virtues of the latter view disappear upon closer inspection, when we take into account the grounds for the facts about truthmaking. The necessitarian enjoys a theoretically simple account of higher-order facts about truthmaking; non-necessitarians face significant challenges, regardless of how they spell out the grounds for their contingent truthmaking facts.

\section{Acknowledgments}

My thanks go to Jack Yip and an anonymous referee for Ergo for their helpful comments. The work described in this paper was substantially supported by a grant from the Research Grants Council of the Hong Kong Special Administrative Region, China (HKU 23400014). 


\section{References}

Armstrong, D. M. (2004). Truth and Truthmakers. Cambridge University Press.

Bigelow, John (1988). The Reality of Numbers: A Physicalist's Philosophy of Mathematics. Clarendon Press.

Briggs, Rachael (2012). Truthmaking Without Necessitation. Synthese 189(1), 11-28.

Cameron, Ross P. (2008). Truthmakers, Realism and Ontology. Philosophy 83(62), 107128.

Goff, Philip (2010). Orthodox Truthmaker Theory Cannot be Defended by Cost/Benefit Analysis. Analysis 70(1), 45-50.

Griffith, Aaron M. (2015). How Negative Truths are Made True. Synthese 192(1), 317-335.

Heil, John (2000). Truth Making and Entailment. Logique et Analyse 43(169-170), 231-242.

Lowe, E. J. (2007). Truthmaking as Essential Dependence. In Jean-Maurice Monnoyer (Ed.), Metaphysics and Truthmakers (237-259). Ontos Verlag.

Martin, C. B. (1996). How it Is: Entities, Absences and Voids. Australasian Journal of Philosophy 74(1), 57-65.

Mellor, D. H. (2003). Real Metaphysics: Replies. In Hallvard Lillehammer and Gonzalo Rodriguez-Pereyra (Eds.), Real Metaphysics: Essays in Honour of D. H. Mellor (212238). Routledge.

Merricks, Trenton (2007). Truth and Ontology. Clarendon Press.

Parsons, Josh (1999). There is no 'Truthmaker' Argument against Nominalism. Australasian Journal of Philosophy 77(3), 325-334.

Rodriguez-Pereyra, Gonzalo (2005). Why Truthmakers. In Helen Beebee and Julian Dodd (Eds.), Truthmakers: The Contemporary Debate (17-31). Clarendon Press.

Rodriguez-Pereyra, Gonzalo (2006). Truthmaking, Entailment, and the Conjunction Thesis. Mind (New Series) 115(460), 957-982.

Schaffer, Jonathan (2008). Truthmaker Commitments. Philosophical Studies 141(1), 7-19.

Schaffer, Jonathan (2010). The Least Discerning and Most Promiscuous Truthmaker. Philosophical Quarterly 6o(239), 307-324.

Sorensen, Roy (2001). Vagueness and Contradiction. Clarendon Press. 